\title{
Genes Associated with Increased Fasting Glucose in Patients with Schizophrenia Spectrum Disorders
}

\author{
Dzana Sudic Hukic ${ }^{1-3 *}$, Eric Olsson ${ }^{4,5}$, Agneta Hilding ${ }^{6}$, Claes-Goran Ostenson ${ }^{6}$, Harvest F Gu ${ }^{6}$, Ewa Ehrenborg ${ }^{7}$, David Erlinge ${ }^{8}$, Gunnar \\ Edman $^{3,4}$, Martin Schalling ${ }^{1,2}$, Catharina Lavebratt ${ }^{1,2}$ and Urban Osby ${ }^{2,3,9}$
}

${ }^{1}$ Neurogenetics Unit, Department of Molecular Medicine and Surgery, Karolinska Institutet, Stockholm, Sweden

${ }^{2}$ Center for Molecular Medicine, Karolinska University Hospital Solna, Stockholm, Sweden

${ }^{3}$ Department of Psychiatry, Tiohundra AB, Norrtalje, Sweden

${ }^{4}$ Department of Clinical Neuroscience, Karolinska Institutet, Stockholm, Sweden

${ }^{5}$ Department of Adult Psychiatry, PRIMA Barn och Vuxenpsykiatri AB, Stockholm, Sweden

${ }^{6}$ Endocrine and Diabetes Unit, Department of Molecular Medicine and Surgery; Karolinska Institute, Stockholm, Sweden

${ }^{7}$ Atherosclerosis Research Unit, Center for Molecular Medicine, Karolinska University Hospital, Stockholm, Sweden

${ }^{8}$ Department of Clinical Sciences, Lund University, Lund, Sweden

${ }^{9}$ Centre for Family Medicine, Department of Neurobiology, Care Sciences and Society, Karolinska institute, Stockholm, Sweden

\begin{abstract}
Background: Metabolic risk factors represent a major cause of increased coronary heart disease morbidity and mortality among psychosis patients. Although antipsychotic medication may lead to hyperglycemia, an association
\end{abstract} to severe mental illness was established before the introduction of antipsychotics.

Methods: We investigated the association between metabolic risk genes and elevated fasting glucose level in patients with schizophrenia spectrum disorder. We applied two association models; (i) case-case where psychosis patients with elevated fasting glucose level $(\geq 5.6 \mathrm{mmol} / \mathrm{l})$ or diagnosed diabetes $(n=263)$ were compared to patients with normal glucose level $(n=389)$, and (ii) case-control model where psychosis patients with elevated fasting glucose level were compared to population-derived controls $(n=494)$. Association analyses were adjusted for age, sex, smoking, family history of diabetes, and waist circumference. (iii) We also investigated whether metabolic genes were associated with schizophrenia spectrum disorder independent of fasting glucose.

Results: No differences between schizophrenia spectrum diagnoses regarding genetic associations with increased fasting glucose were detected. In a case-case model, a genetic variant in IGF2BP2 was associated with elevated fasting glucose level among persons with schizophrenia spectrum disorder. In a case-control model associations were found with genetic variants in the NOTCH2, THADA, WFS1, P2RX7, and MNTR1B. A genetic variant in PPARD was nominally associated with schizophrenia spectrum disorder independent of glucose level.

Conclusion: Our findings indicate that common metabolic polymorphisms associated with elevated fasting glucose among schizophrenia spectrum disorder patients may at least partially be explained by increased vulnerability in schizophrenia spectrum disorders for genes associate with elevated fasting glucose in the population.

Keywords: Psychosis; Fasting glucose; Metabolic risk genes; Casecase; Case-control; Genetic association studies

\section{Introduction}

Schizophrenia is a severe psychiatric disorder characterized by ubiquitous psychotic features and symptoms such as disorganized thinking and behavior, representing social dysfunction. Symptoms overlap with other psychiatric disorders and schizophrenia is often considered as a broad spectrum disorder. Familial studies support strong heritability, estimated to 68 to 89 percent [1], and a number of genes have been shown to be associated with schizophrenia, although the effect sizes are limited.

Schizophrenia is the psychiatric disorder associated with the largest health care use [2]. In Sweden, a recent study showed that in schizophrenia life expectancy is reduced by 19 years for men and 17 years for women compared to the population [3]. Severe mental illness including schizophrenia has been shown to be associated with a significant excess of somatic illnesses including increased risk for hyperglycemia and diabetes type 2, evident long before the introduction of antipsychotic drugs, which however have further increased the diabetes risk, resulting in a more than doubled risk of dying from cardiovascular causes of death compared with the general population [4]. Although suicide rates are highly elevated in this group of patients, increased cardiovascular causes of death, not suicide, is the major contributor to excess mortality $[4,5]$.

In a previous clinical study of metabolic risk in persons with schizophrenia or other psychosis compared with the population, we reported that psychosis per se was an important and independent risk factor for increased fasting glucose, controlling for differences in waist circumference, gender, age, blood pressure, tobacco use and family history of diabetes (OR 2.41, 95\% CI 1.84-3.14) [6]. This increased diabetes risk could be mediated by hereditary factors, indicated by shared genetic vulnerability for diabetes type 2 and schizophrenia, thus motivating further genetic studies of diabetes risk in psychosis.

*Corresponding author: Dzana Sudic Hukic, Neurogenetics Unit, Department of Molecular Medicine and Surgery, Karolinska Institutet, Stockholm, Sweden, Tel: +46 851776402; E-mail: dzana.hukic@ki.se

Received December 22, 2014; Accepted February 21, 2015; Published February 28,2015

Citation: Hukic DS, Olsson E, Hilding A, Ostenson CG, Gu HF, et al. (2015) Genes Associated with Increased Fasting Glucose in Patients with Schizophrenia Spectrum Disorders. J Diabetes Metab 6: 512. doi:10.4172/2155-6156.1000512

Copyright: $\odot 2015$ Hukic DS, et al. This is an open-access article distributed under the terms of the Creative Commons Attribution License, which permits unrestricted use, distribution, and reproduction in any medium, provided the original author and source are credited. 
Citation: Hukic DS, Olsson E, Hilding A, Ostenson CG, Gu HF, et al. (2015) Genes Associated with Increased Fasting Glucose in Patients with Schizophrenia Spectrum Disorders. J Diabetes Metab 6: 512. doi:10.4172/2155-6156.1000512

Page 2 of 7

The aims of the present study were to test in the same clinical patient material as the previous clinical study if reported genetic metabolic risk variants in the population were associated with elevated fasting glucose in schizophrenia spectrum patients in (i) case-case and (ii) case-control models, and (iii) to test if genetic metabolic risk variants were associated with schizophrenia spectrum disorder irrespective of glucose levels.

\section{Materials and Methods}

\section{Ethics approval}

Ethical approval was obtained from the Stockholm Regional Ethics Committee (Regionala etikprövningsnämnden i Stockholm) for both cases and controls. All patients and controls gave informed consent to participate.

\section{Patients from the swedish study of metabolic risks in psychosis (SMRP)}

Psychosis patients were participants from the Swedish study of Metabolic Risks in Psychosis (SMRP), recruited from specialized psychosis outpatient clinics mainly in Stockholm County, Sweden. These clinics are responsible for treatment of all outpatients with long-term psychotic disorders and especially schizophrenia in each catchment area. As part of a general health screening, all patients in clinical treatment from each clinic were asked to participate in the study. Clinical diagnoses were confirmed by an experienced clinician according to the Diagnostic and Statistical Manual of Mental disorders, $4^{\text {th }}$ Ed. (DSM-IV). In the present study, 652 patients were included (Table 1). Of the 652 patients, $52 \%$ were men. Mean $( \pm S D)$ age was $47( \pm 12)$ years. Mean waist circumference was $97( \pm 15) \mathrm{cm}$ for women and $104( \pm 15) \mathrm{cm}$ for men. Current smokers were 235 patients (36\%). Positive family history of diabetes was present for 150 patients (23\%). Of those 652 patients, $389(60 \%)$ had normal fasting glucose $(f$-pg $<5.6 \mathrm{mmol} / \mathrm{L})$, and $235(36 \%)$ had elevated fasting glucose $(f$-pg $\geq 5.6 \mathrm{mmol} / \mathrm{L})$ while $28(4 \%)$ were on drug treatment for diabetes. Patients were assessed with self-reported questionnaires on number and length of hospital admissions, age at disease onset, and duration of antipsychotic treatment and also asked about tobacco and alcohol use, and concomitant somatic disease. Data on diagnosis, level of functioning (Global Assessment on Functioning (GAF) and Clinical Global Impression (CGI)) and dosage and type of all medication was obtained. Blood pressure, weight, height and waist circumference were measured. Patients were given written instructions to fast overnight before the venous blood sampling. Serum glucose was assayed using the glucose oxidase method.

\section{Stockholm diabetes prevention program controls (SDPP)}

Control subjects were selected from the population based prospective Stockholm Diabetes Prevention Program (SDPP) [7], which comprised of 7949 participants selected in a population based way. Participants were included during 1992-1998. A follow up was performed eight to ten years later (2002-2006), and 5712 individuals (3329 women and 2383 men), 72\% of baseline participants, took part. At inclusion, only subjects without known diabetes were enrolled. Half of the subjects had a positive family history for type two diabetes (FHD), defined as at least one first-degree relative with known diabetes. SDPP subjects were assessed both at inclusion and follow up with questionnaires on lifestyle factors, physical activity, tobacco and alcohol use, socioeconomic status, and psychosocial conditions. Data on weight, height, waist circumference, blood pressure, and fasting serum glucose was obtained. At follow up, 997 individuals
(17\%) had increased fasting glucose levels $(f$-pg $\geq 5.6 \mathrm{mmol} / \mathrm{L}$ ) and 289 individuals (5\%) were diagnosed with type 2 diabetes. From the SDPP follow up sample, 494 SDPP control subjects were selected for genetic association study. 404 individuals (82\%) had normal fasting glucose levels, 66 (13\%) had increased fasting glucose levels, and 24 (5\%) were diagnosed with type 2 diabetes.

\section{DNA preparation and genotyping}

For the patients and controls, venous blood was drawn from each individual. DNA was extracted according to standard procedures. The genotyping process was performed on Open Array Real-Time PCR System Instrument (Applied Biosystems, Foster City, CA, USA). Allelic discrimination was performed with the TaqMan Genotype Software (Applied Biosystems).

\section{Genetic markers assessed}

Several SNPs were analyzed (Supplemental Table 1). Hardy Weinberg Equilibrium p-value cut-off was $\mathrm{p} \leq 0.05$ for both cases and controls. Candidate genes and genetic variants that had previously reported genome-wide significance levels and were reproducibly associated with type 2 diabetes and cardiovascular disorders were selected: NOTCH2 (rs10923931), THADA (rs7578597), ADMTS9 (rs4607103), IGF2BP2 (rs4402960), PPARG (rs1801282), CDKAL1 (rs7754840), JAZF1 (rs864745), SLC30A8 (rs13266634), CDKN2B (rs1081161), Nearest gene association- CDC123 (rs12779790) Nearest gene association- HHEX (rs1111875), IDE (rs2251101), TCF7L2 (rs7903146), KCNJ11 (rs5219), KCNQ1 (rs2237892), MTRN1B (rs10830963), Nearest gene association- TSPAN8/LGR5 (rs79611581),

\begin{tabular}{|c|c|c|c|}
\hline & $\begin{array}{c}\text { Psychosis f-PG } \\
\geq 5.6\end{array}$ & $\begin{array}{l}\text { Psychosis } \\
\text { f-PG }<5.6\end{array}$ & SDPP controls \\
\hline Total & 263 & 389 & 494 \\
\hline Men [n (\%)] & $150(57)$ & $192(49)$ & $267(54)$ \\
\hline Age, (mean, range) & $52(22-82)$ & $45(19-84)$ & $56(44-66)$ \\
\hline $\begin{array}{c}\text { Waist women, } \mathrm{cm} \text { (mean } \\
\pm \mathrm{SD})\end{array}$ & $101 \pm 19.5$ & $90.6 \pm 21.5$ & $89.6 \pm 13.1$ \\
\hline Waist $\geq 80 \mathrm{~cm}[\mathrm{n}(\%)]$ & $106(93)$ & $158(80.2)$ & $170(74.9)$ \\
\hline Waist man, $\mathrm{cm}$ (mean $\pm \mathrm{SD})$ & $106 \pm 19.6$ & $100.2 \pm 20.0$ & $99.5 \pm 10.8$ \\
\hline Waist $\geq 94 \mathrm{~cm}[\mathrm{n}(\%)]$ & $123(82.0)$ & $130(67.7)$ & $177(66.3)$ \\
\hline f-PG, mmol/l (mean \pm SD) & $6.7 \pm 1.8$ & $5.0 \pm 0.33$ & $5.1 \pm 0.79$ \\
\hline $\mathrm{f}-\mathrm{PG} \geq 5.6 \mathrm{mmol} / \mathrm{L}[\mathrm{n}(\%)]$ & 263 & - & $66(13)$ \\
\hline \multicolumn{4}{|l|}{ Smoking [n (\%)] } \\
\hline Never & $81(31)$ & $166(43)$ & $237(48)$ \\
\hline Former & $73(28)$ & $92(24)$ & $167(34)$ \\
\hline Current & $109(41)$ & $126(32)$ & $89(18)$ \\
\hline Missing & - & $5(1)$ & $1(<1)$ \\
\hline \multicolumn{4}{|l|}{$\begin{array}{l}\text { Family history of diabetes } \\
\text { [n (\%)] }\end{array}$} \\
\hline No & $158(60)$ & $277(71)$ & $309(63)$ \\
\hline Yes & $72(27)$ & $78(20)$ & $185(37)$ \\
\hline Missing & $33(13)$ & $34(9)$ & - \\
\hline \multicolumn{4}{|l|}{$\begin{array}{l}\text { Psychiatric diagnoses [n } \\
(\%)]\end{array}$} \\
\hline Schizophrenia & $159(61)$ & $192(49)$ & - \\
\hline Schizoaffective disorder & $29(11)$ & $39(10)$ & - \\
\hline Delusional disorder & $19(7)$ & $21(5)$ & - \\
\hline Psychosis NOS & $24(9)$ & $66(17)$ & - \\
\hline Bipolar disorder & $18(7)$ & $22(6)$ & - \\
\hline Other psychiatric disorders & $14(5)$ & $49(13)$ & - \\
\hline
\end{tabular}

Table 1: Clinical characteristics of the schizophrenia spectrum and contro samples. 
Citation: Hukic DS, Olsson E, Hilding A, Ostenson CG, Gu HF, et al. (2015) Genes Associated with Increased Fasting Glucose in Patients with Schizophrenia Spectrum Disorders. J Diabetes Metab 6: 512. doi:10.4172/2155-6156.1000512

Page 3 of 7

HNF1A (rs2259816), FTO (rs8050136) [8-16], and associated with cardiovascular disorders CELSR2 (rs646776), MIA3 (rs17465637), No gene association (rs2943634), MRAS (rs9818870), MTHFDIL (rs6922269), CDKN2B (rs4977574), CXCL12 (rs1746048), SMAD3 (rs17228212) [17-21].

In addition, a number of common genetic variants were selected based on previous reports to be associated with type 2 diabetes and cardiovascular disorders with inconsistent and varied results, thus there was interest in further studies of the effects of the variants. Genetic variants of WFS1 (rs10010131) and EXT2 (rs11037909, rs1113132, rs37408788) were significantly associated with type 2 diabetes in several studies [15,22,23]. Genetic variants of MTTP (rs1800804) and PPARD (rs1053049, rs2016520, rs2076167, rs34474204, rs6902123) were selected since they have been shown to be involved in ischemic heart disease, glucose and lipid metabolism [24-29]. Likewise, genetic variants near HHEX (rs7923837, and rs1544210) were associated with type 2 diabetes in several linkage studies $[15,19,30]$. Genetic variants of CAMKK2 (rs3817190) and P2RX7 (rs1718119, rs2230912, rs3751143) were associated with reduced risk of ischemic heart disease [31].

\section{Statistical analyses}

Differences in fasting glucose level between psychosis diagnoses were analyzed using ANOVA and significant effects were further investigated with Fisher's least significant difference (LSD) post hoc analysis for multiple comparisons. ANOVA tests were performed in IBM SPSS Staticstics 22.The cut off level for fasting plasma glucose level $(f-\mathrm{pg}<5.6 \mathrm{mmol} / \mathrm{L})$ was defined according to the recently proposed criteria from the International Diabetes Federation (IDF); (www.idf. org/webdata/docs/Metabolic_syndrome definition.pdf). Patients were analyzed for allelic association in a case-case model where psychosis patients with elevated fasting glucose level were compared to psychosis patients with normal glucose level, and also in a case-control model where psychosis patients with elevated fasting glucose level were compared to control subjects from the follow up of the SDPP study. In both models, logistic regression was used to test for allelic association, where gender, age, smoking, waist circumference, and family history of diabetes were used as covariates. Associations were corrected for multiple testing by calculating the False discovery rate (FDR) according to the method by Benjamin Hochberg. To test the relationship between antipsychotic drug and the genetic associations, analyses restricted to patients on clozapine $(n=62)$ were performed. The allelic distribution for all psychosis patients was compared to SDPP controls, where gender, age, smoking, waist circumference, family history of diabetes, and fasting glucose level were used as covariates.

All calculations were performed using PLINK in BC|SNPmax data management and analysis (http://pngu.mgh.harvard.edu/purcell/ plink/) [32]. The level of nominal significance was 5 percent (twotailed).

\section{Results}

All SNPs were in Hardy Weinberg equilibrium. No differences between schizophrenia spectrum disorder diagnoses regarding fasting glucose level were detected. The genetic polymorphisms nominally associated with elevated fasting glucose levels among schizophrenia spectrum disorder patients were located in IGF2BP2 in the case-case model, and in NOTCH2, THADA, WFS1, P2RX7, and MTNR1B in the case-control model (Table 2). Genetic effect sizes were lower, although not statistically significantly, for patients on clozapine compared to all patients with increased fasting glucose levels (Table 3 ). The genetic polymorphism in PPRAD was nominally associated to schizophrenia spectrum disorder independent of glucose level. None of the relationships survived correction for multiple testing of 43 SNPs.

\section{Genetic findings in case-case analyses: IGF2BP2}

In the case-case analysis of IGF2BP2, the minor allele $\mathrm{T}$ of rs4402960 (odds ratio $(\mathrm{OR})=0.72, \mathrm{p}=0.019$ ) was less common among the psychosis patients with elevated fasting glucose levels. Thus, the major allele $\mathrm{G}$ in $\mathrm{rs} 4402960(\mathrm{OR}=1.39, \mathrm{p}=0.019)$ was nominally associated with elevated fasting glucose levels (Table 2).

\section{Genetic findings in case-control analyses}

\section{NOTCH2, THADA, WFS1, P2RX7, and MNTR1B}

In the case-control analysis, where controls were SDPP subjects, the minor allele $\mathrm{T}$ of $\mathrm{rs} 10923931(\mathrm{OR}=1.84, \mathrm{p}=0.011)$ in the NOTCH2 gene was nominally associated with elevated fasting plasma glucose levels. Likewise, the minor allele $\mathrm{G}$ of $\mathrm{rs} 10830963$ (OR=1.51, $\mathrm{p}=0.0039)$ in the $M N T R 1 B$ gene was associated with elevated fasting glucose levels. The minor allele $\mathrm{C}$ of $\mathrm{rs} 7578597(\mathrm{OR}=0.55, \mathrm{p}=0.014)$ and the minor allele $\mathrm{A}$ of $\mathrm{rs} 10010131$ (OR=0.71, $\mathrm{p}=0.010)$ in THADA and WFS1, respectively, and the minor allele A of $\mathrm{rs} 1718119(\mathrm{OR}=0.72, \mathrm{p}=0.014)$ in the $P 2 R X 7$ gene were less common among psychosis patients with elevated fasting plasma glucose. Thus, the major allele $\mathrm{T}$ of $\mathrm{rs} 7578597$ (OR=1.85, $\mathrm{p}=0.014)$ in THADA, the major allele $\mathrm{G}$ of $\mathrm{rs} 10010131 \quad(\mathrm{OR}=1.43$ $\mathrm{p}=0.010)$ in the WFS1 gene, and the major allele $\mathrm{G}$ of rs1718119

\begin{tabular}{|c|c|c|c|c|c|c|c|c|c|c|}
\hline & & & & $\begin{array}{c}\text { Psychosis f-PG } \\
\geq 5.6\end{array}$ & $\begin{array}{l}\text { Psychosis } \\
\text { f-PG }<5.6\end{array}$ & $\begin{array}{l}\text { SDPP } \\
\text { controls }\end{array}$ & & & & \\
\hline & Gene & SNP & $\begin{array}{l}\text { Minor/major } \\
\text { allele }\end{array}$ & $(a a / a b / b b) \%$ & $(\mathrm{aa} / \mathrm{ab} / \mathrm{bb}) \%$ & $(a a / a b / b b) \%$ & Allele $^{a}$ & OR $[95 \% \mathrm{Cl}]^{\mathrm{b}}$ & $\mathbf{P}^{\mathrm{c}}$ & BH FDR $^{d}$ \\
\hline $\begin{array}{l}\text { Psychosis } f-P G \geq 5.6 \text { vs } \\
\text { Psychosis } f-P G<5.6\end{array}$ & IGF2BP2 & rs4402960 & $\mathrm{T} / \mathrm{G}$ & $8 / 45 / 47$ & $13 / 48 / 39$ & $12 / 40 / 48$ & G & 1.39 [1.05-1.74] & 0.019 & 0.76 \\
\hline \multirow[t]{5}{*}{$\begin{array}{l}\text { Psychosis f-PG } \geq 5.6 \text { vs } \\
\text { SDPP controls }\end{array}$} & $\mathrm{NOTCH} 2$ & rs10923931 & $\mathrm{T} / \mathrm{G}$ & 2/19/79 & $1 / 15 / 84$ & $0 / 15 / 85$ & $\mathrm{~T}$ & $1.84[1.13-2.46]$ & 0.011 & 0.18 \\
\hline & THADA & rs7578597 & $\mathrm{C} / \mathrm{T}$ & $2 / 11 / 87$ & $<1 / 16 / 83$ & $<1 / 19 / 80$ & $\mathrm{~T}$ & $1.81[1.00-2.26]$ & 0.014 & 0.18 \\
\hline & WFS1 & rs10010131 & $\mathrm{A} / \mathrm{G}$ & $19 / 42 / 39$ & $17 / 50 / 33$ & $20 / 48 / 32$ & $\mathrm{G}$ & 1.40 [1.03-1.69] & 0.010 & 0.18 \\
\hline & $P 2 R X 7$ & rs1718119 & $A / G$ & $11 / 43 / 46$ & $19 / 45 / 36$ & $19 / 46 / 35$ & $\mathrm{G}$ & $1.38[1.21-1.89]$ & 0.014 & 0.18 \\
\hline & MTNR1B & rs10830963 & $\mathrm{G} / \mathrm{C}$ & $10 / 42 / 48$ & $8 / 37 / 55$ & $6 / 34 / 60$ & G & 1.51 [1.16-1.89] & 0.0039 & 0.17 \\
\hline
\end{tabular}

aAllele associated with elevated fasting glucose in psychosis patients

${ }^{\mathrm{b}} \mathrm{OR}$ calculated for the allele associated with hyperglycemia in psychosis patients

${ }^{\mathrm{c} A d j u s t e d}$ for age, gender, smoking, waist circumference, and family history of diabetes

${ }^{\mathrm{d} B e n j a m i n}$ Hochberg False discovery rate correction

Table 2: Allelic association with metabolic risk genes in psychosis patients with elevated fasting glucose, $f$-PG $\geq 5.6$ compared to psychosis patients with normal fasting plasma glucose $(f-P G<5.6)$ and to SDPP controls. 


\begin{tabular}{|c|c|c|c|}
\hline $\begin{array}{c}\text { Psychosis f-PG } \geq 5.6 \text { vs } \\
\text { Psychosis f-PG<5.6 }\end{array}$ & Gene & SNP & OR [95\% Cl] \\
\hline $\begin{array}{c}\text { Psychosis f-PG } \geq \mathbf{5 . 6} \text { vs. SDPP } \\
\text { controls }\end{array}$ & NOTCH2 & rs10923931 & $1.33[0.57-2.94]$ \\
\hline & THADA & rs 7578597 & $1.78[0.69-4.44]$ \\
\hline & WFS1 & rs 10010131 & $0.90[0.71-1.75]$ \\
\hline & P2RX7 & rs 1718119 & $1.29[0.81-2.12]$ \\
\hline & MTNR1B & rs10830963 & $1.47[0.92-2.48]$ \\
\hline
\end{tabular}

Table 3: Odds ratios (OR) calculated for psychosis patients on clozapine treatment analyzed for alleles associated with elevated fasting glucose in Table 2

$(\mathrm{OR}=1.40, \mathrm{p}=0.014)$ in the $P 2 R X 7$ gene were nominally associated with elevated fasting glucose levels compared to SDPP controls (Table 2).

\section{The effect of clozapine treatment}

For the SNPs with nominal association to elevated fasting glucose level in our material (cf. above), ORs were calculated for the SNPglucose level relationships restricting the patients to those treated with clozapine, (Table 3). In the case-case analysis, OR for rs4402960 in IGF2BP2 was 1.15. In the case-control analysis the following SNP ORs were found: for rs10923931 in $\mathrm{NOTCH} 2(\mathrm{OR}=1.33)$, for $\mathrm{rs} 7578597$ in THADA (OR=1.78), for rs7578597 in THADA (OR=0.90), for rs1718119 in $P 2 R X 7(\mathrm{OR}=1.29)$, and for rs10830963 in MTNR1B $(\mathrm{OR}=1.47)$ (Table 3$)$.

\section{Genetic associations regardless of fasting glucose levels: PPARD}

The minor allele $\mathrm{T}$ of $\mathrm{rs} 34474204(\mathrm{OR}=0.54, \mathrm{p}=0.015)$ was less common among the psychosis patients. Thus, the major allele $\mathrm{C}$ in $\mathrm{rs} 34474204(\mathrm{OR}=1.86, \mathrm{p}=0.015)$ was nominally associated with psychosis irrespective of glucose level.

\section{Discussion}

\section{Main findings}

The main findings of this study were that elevated fasting glucose levels in patients with schizophrenia spectrum disorders were nominally associated with a SNP in the IGF2BP2 gene when compared with patients with normal fasting glucose levels, and with SNPs in the NOTCH2, THADA, WFS1, P2RX7, and MNTR1B genes in comparison with the population. Both analyses were adjusted for metabolic risk factors. Further, the PPARD gene was nominally associated with schizophrenia spectrum disorder irrespective of fasting glucose level.

\section{Strengths and limitations}

Psychosis illnesses such as schizophrenia spectrum disorders are clinically defined, thus there is limited knowledge of disease biology. Heterogenous clinical symptoms, which may be related to separate biological processes, are likely to contribute to differences in genetic diversity and hampers the identification of major genetic loci associated with psychotic disorders. In addition, there is a genetic overlap with other psychiatric disorders, especially bipolar disorder. However, use of the case-case model in genetic analyses helps to reduce clinical heterogeneity and environmental differences between mental disorder groups [33]. The case-case model may represent a narrow subgroup of psychosis patients, more biologically correlated and hence more related to susceptibility genes than psychosis patients in general [34]. In the present study, we applied both a case-case and a case-control design.

The patient sample was recruited from psychosis outpatient clinics mainly in Stockholm County, Sweden. All patients in each participating clinic were invited to participate. In an analysis from one clinic the attrition rate was $23 \%$. There were no differences in weight or BMI between those who participated and those who declined, but those who declined were older ( 52 vs. 48 years) [6]. No differences between diagnoses regarding fasting glucose were detected, thus different diagnoses were analyzed as one group. Family history of diabetes (FHD) was present in $23 \%$ of the patients, which is similar to the prevalence in general population for moderate familial risk [35]. The controls were selected to represent the whole SDPP cohort including $5 \%$ with diagnosed diabetes and $17 \%$ with increased fasting glucose levels. In our analyses, we adjusted for differences in FHD between patients and SDPP controls.

There are no strong internal genetic limits in the current Swedish population [36], and especially the middle/southern parts of Sweden, from where the participants of this study are derived, are genetically homogeneous [37]. None of the relationships found here survived correction for multiple testing. However, the study was not an exploratory investigation but an investigation based on a number of hypotheses. Thus, the correction for multiple testing might be regarded as stringent.

\section{Findings from other studies}

To date, the identification of major genetic polymorphisms for diabetes type 2 and psychosis have had limited success. The prevalence of diabetes among psychosis patients is about two times as high compared to the prevalence reported in the population [38,39]. Hyperglycemia, obesity, hypertension, and dyslipidemia have been associated with schizophrenia [40], and represent major causes of increased coronary heart disease morbidity and mortality among psychosis patients [41]. An increased prevalence of diabetes type 2 has been reported in first episode drug-naïve psychosis patients [42], and also in unaffected first-degree relatives of people with schizophrenia [43,44]. In addition, a recently published study shows that family history of diabetes increases the prevalence of diabetes twofold when compared with persons without family history of diabetes [45]. On the other hand, the atypical antipsychotics are associated with weight gain, diabetes, insulin resistance and the metabolic syndrome [46], thus implicating that antipsychotic medication increases the risk of comorbidity in such patients. The underlying mechanisms of antipsychotics are still unclear. However, non-obese psychosis patients treated with clozapine and olanzapine show insulin resistance [47], suggesting antipsychotic induced insulin resistance occurs independently of weight gain. Interestingly, an animal model study reports harmful metabolic effects of clozapine and association with insulin resistance and hyperglycemia, without changes in body weight, suggesting antipsychotic induced insulin resistance occur independently of weight gain. Furthermore, increase in hepatic phosphorylase activity, and increase expression level of glucose-6-phosphatase are seen, suggesting it as a possible underlying mechanism of a clozapine-induced insulin resistance and hyperglycemia [48].

Insulin-like growth factor II mRNA binding protein 2 gene, $I G F 2 B P 2$, is highly expressed in the pancreatic islets region, and plays a role in RNA localization, stability and translation of IGF-2 [49]. Particularly the genetic variation studied here, rs4402960 with a G $\rightarrow$ T substitution, is associated with diabetes type 2 in several studies [50] and with reduced beta cell function and insulin resistance [51]. In addition, a recent replicated study reports an association of the diabetic nephropathy and genetic polymorphism rs 4402960 only in males with diabetes type 1 [52-54]. 
The melatonin receptor $1 \mathrm{~B}$ gene, MNTR1B, mainly expressed in the beta cells, is associated with increased fasting glucose level, with the strongest effect on reduced insulin secretion and sensitivity [55]. In addition, insulin secretion is inhibited by melatonin [12]. In support of our results, allele $\mathrm{G}$ of $M N T R 1 B$ rs10830963 was associated with diabetes type 2 risk, as well as with increased MNTR1B expression [12]. Moreover, among overweight children reports the $G$ allele of rs10830963 associated with elevated glucose level, independent of age and body mass index (BMI) [56].

Genetic variation in the purinergic receptor gene, $P 2 R X 7$, has been associated with mood disorders [57,58], ischemic stroke and with myocardial infarction in smokers [31]. In support of our finding, the allele $\mathrm{G}$ of the non-synonymous variation rs1718119 showed a gain-offunction phenotype, and fibroblasts from type 2 diabetes patients are characterized by increased purinergic activity $[59,60]$.

Wolfram syndrome 1 gene, WFS1, is highly expressed in beta cells and encodes for a transmembrane protein localized in endoplasmic reticulum (ER) that is expressed in various tissue, including the brain. Genetic variants, e.g. allele $G$ of rs10010131, have been associated with diabetes type 2 [23]. Recently, a novel non synonymous genetic variant of WFS1 gene is found to segregate completely with the diabetic phenotype $[61,62]$.

The thyroid adenoma associated gene, THADA, and the allele $\mathrm{T}$ of rs7578597 are associated with increased risk of diabetes type 2 related progressions [63].

The neurogenic locus notch homolog 2 gene, $\mathrm{NOTCH} 2$, encodes for the transmembrane protein. Notch signaling pathway is important for the neuronal function and development [64]. The $\mathrm{T}$ allale of rs10923931 in the NOTCH2 is the strongest SNP-risk allele associated with type 2 diabetes [16].

The peroxisome proliferator-activated receptors (PPARs), including PPAR-delta (D), are nuclear hormone receptors acting as transcription factors. Genetic variation of PPARD has been associated with both fasting glucose level, obesity $[65,66]$, and schizophrenia [66,67]. Moreover, fatty acids are ligands for PPARD [68], and lower level of essential polyunsaturated fatty acids are associated with severe symptoms in drug naïve schizophrenia patients [69].

Among the different antipsychotic drugs, it is known that clozapine is associated with hyperglycemia and the weight gain, also in our patient sample [38]. To test the effects of antipsychotic medication on our here reported genetic associations, analyses were performed restricted to patients medicating with clozapine $(n=62)$. The results suggested that the impact of antipsychotic drugs on SNP-glucose level associations was limited.

Glucose disturbances and diabetes type 2 are prevalent in patients with schizophrenia spectrum disorders. These findings long predate the introduction of antipsychotic drugs. The roles of here investigated genes in the pathophysiology of diabetes type 2 or psychosis are still unclear. The reported findings from this study may at least partially be explained by an increased vulnerability in schizophrenia spectrum disorders for genes associated with elevated fasting glucose level in the population.

\section{Acknowledgments}

Dr. Urban Osby has research collaboration with Lundbeck A/S, and Dr. Eric Olsson was supported by a grant from PRIMA Child and Adult Psychiatry Inc.

The Swedish Study of Metabolic Risks in Psychosis (SMP) was supported by ALF Grants 20060100, 20080022 and 20110560 from Stockholm County Council and Karolinska institute, grants from Soderstrom-Konigska Hospital, Karolinska Institute's Faculty Funds, the Swedish Research Council (grant 2010-3631), and the Fredrik and Ingrid Thurings Foundation.

The Stockholm Diabetes Prevention Program (SDPP) was supported by grants from Stockholm County Council, the Swedish Research Council, the Swedish Council for Working Life and Social Research, the Swedish Diabetes Association and Novo Nordisk Scandinavia.

We thank all the patients who participated in this study. The authors would also like to thank research assistant Carina Schmidt for skillful assistance in managing the data base and the biological samples.

\section{References}

1. DE Hert M, Correll CU, Bobes J, Cetkovich-Bakmas M, Cohen D, et al. (2011) Physical illness in patients with severe mental disorders. I. Prevalence, impact of medications and disparities in health care. World Psychiatry 10: 52-77.

2. Wu EQ, Birnbaum HG, Shi L, Ball DE, Kessler RC, et al. (2005) The economic burden of schizophrenia in the United States in 2002. J Clin Psychiatry 66 1122-1129.

3. Osby U, Brandt L, Correia N, Ekbom A, Sparén P (2001) Excess mortality in bipolar and unipolar disorder in Sweden. Arch Gen Psychiatry 58: 844-850.

4. Hennekens $\mathrm{CH}$, Hennekens AR, Hollar D, Casey DE (2005) Schizophrenia and increased risks of cardiovascular disease. Am Heart J 150: 1115-1121.

5. Osby U, Correia N, Brandt L, Ekbom A, Sparén P (2000) Mortality and causes of death in schizophrenia in Stockholm county, Sweden. Schizophr Res 45 21-28.

6. Osby U, Olsson E, Edman G, Hilding A, Eriksson SV, et al. (2014) Psychotic disorder is an independent risk factor for increased fasting glucose and wais circumference. Nord J Psychiatry 68: 251-258.

7. Eriksson AK, Ekbom A, Granath F, Hilding A, Efendic S, et al. (2008) Psychological distress and risk of pre-diabetes and Type 2 diabetes in a prospective study of Swedish middle-aged men and women. Diabet Med 25: 834-842.

8. Diabetes Genetics Initiative of Broad Institute of $\mathrm{H}$, Mit LU, Novartis Institutes of BioMedical R, Saxena R, Voight BF, et al. (2007) Genome-wide association analysis identifies loci for type 2 diabetes and triglyceride levels. Science 316 $1331-1336$.

9. Saxena R, Elbers CC, Guo Y, Peter I, Gaunt TR, et al. (2012) Large-scale gene-centric meta-analysis across 39 studies identifies type 2 diabetes loci. Am J Hum Genet 90: 410-425.

10. Voight BF, Scott LJ, Steinthorsdottir V, Morris AP, Dina C, et al. (2010) Twelve type 2 diabetes susceptibility loci identified through large-scale association analysis. Nat Genet 42: 579-589.

11. Zeggini E, Weedon MN, Lindgren CM, Frayling TM, Elliott KS, et al. (2007) Replication of genome-wide association signals in UK samples reveals risk loci for type 2 diabetes. Science 316: 1336-1341.

12. Lyssenko V, Nagorny CL, Erdos MR, Wierup N, Jonsson A, et al. (2009) Common variant in MTNR1B associated with increased risk of type 2 diabetes and impaired early insulin secretion. Nat Genet 41: 82-88.

13. Prokopenko I, Langenberg C, Florez JC, Saxena R, Soranzo N, et al. (2009) Variants in MTNR1B influence fasting glucose levels. Nat Genet 41: 77-81.

14. Scott LJ, Mohlke KL, Bonnycastle LL, Willer CJ, Li Y, et al. (2007) A genomewide association study of type 2 diabetes in Finns detects multiple susceptibility variants. Science 316: 1341-1345

15. Sladek R, Rocheleau G, Rung J, Dina C, Shen L, et al. (2007) A genome-wide association study identifies novel risk loci for type 2 diabetes. Nature 445: 881 885 .

16. Zeggini E, Scott LJ, Saxena R, Voight BF, Marchini JL, et al. (2008) Metaanalysis of genome-wide association data and large-scale replication identifies additional susceptibility loci for type 2 diabetes. Nat Genet 40: 638-645.

17. Kathiresan S, Melander O, Guiducci C, Surti A, Burtt NP, et al. (2008) Six new loci associated with blood low-density lipoprotein cholesterol, high-density lipoprotein cholesterol or triglycerides in humans. Nat Genet 40: 189-197.

18. Myocardial Infarction Genetics Consortium, Kathiresan S, Voight BF, Purcell S, Musunuru K, et al. (2009) Genome-wide association of early-onset myocardial 
Citation: Hukic DS, Olsson E, Hilding A, Ostenson CG, Gu HF, et al. (2015) Genes Associated with Increased Fasting Glucose in Patients with Schizophrenia Spectrum Disorders. J Diabetes Metab 6: 512. doi:10.4172/2155-6156.1000512

Page 6 of 7

infarction with single nucleotide polymorphisms and copy number variants. Nat Genet 41: 334-341.

19. Nordman S, Ostenson CG, Efendic S, Gu HF (2009) Loci of TCF7L2, HHEX and IDE on chromosome $10 \mathrm{q}$ and the susceptibility of their genetic polymorphisms to type 2 diabetes. Exp Clin Endocrinol Diabetes 117: 186-190.

20. Sabatti C, Service SK, Hartikainen AL, Pouta A, Ripatti S, et al. (2009) Genome-wide association analysis of metabolic traits in a birth cohort from a founder population. Nat Genet 41: 35-46.

21. Samani NJ, Erdmann J, Hall AS, Hengstenberg C, Mangino M, et al. (2007) Genomewide association analysis of coronary artery disease. N Engl J Med 357: 443-453.

22. Liu L, Yang X, Wang H, Cui G, Xu Y, et al. (2013) Association between variants of EXT2 and type 2 diabetes: a replication and meta-analysis. Hum Genet 132 : $139-145$

23. Cheng S, Wu Y, Wu W, Zhang D (2013) Association of rs734312 and rs10010131 polymorphisms in WFS1 gene with type 2 diabetes mellitus: a meta-analysis. Endocr J 60: 441-447.

24. Aminoff A, Ledmyr H, Thulin P, Lundell K, Nunez L, et al. (2010) Allele-specific regulation of MTTP expression influences the risk of ischemic heart disease. $J$ Lipid Res 51: 103-111.

25. Ledmyr H, Karpe F, Lundahl B, McKinnon M, Skoglund-Andersson C, et al. (2002) Variants of the microsomal triglyceride transfer protein gene are associated with plasma cholesterol levels and body mass index. J Lipid Res 43: 51-58.

26. Karpe F, Lundahl B, Ehrenborg E, Eriksson P, Hamsten A (1998) A common functional polymorphism in the promoter region of the microsomal triglyceride transfer protein gene influences plasma LDL levels. Arterioscler Thromb Vasc Biol 18: 756-761.

27. Grarup N, Albrechtsen A, Ek J, Borch-Johnsen K, Jørgensen T, et al. (2007) Variation in the peroxisome proliferator-activated receptor delta gene in relation to common metabolic traits in 7,495 middle-aged white people. Diabetologia 50: $1201-1208$

28. Karpe F, Ehrenborg EE (2009) PPARdelta in humans: genetic and pharmacological evidence for a significant metabolic function. Curr Opin Lipido 20: $333-336$

29. Kotronen A, Yki-Järvinen H, Aminoff A, Bergholm R, Pietiläinen KH, et al. (2009) Genetic variation in the ADIPOR2 gene is associated with liver fat content and its surrogate markers in three independent cohorts. Eur J Endocrinol 160: 593602

30. Staiger H, Machicao F, Stefan N, Tschritter O, Thamer C, et al. (2007) Polymorphisms within novel risk loci for type 2 diabetes determine beta-cel function. PLoS One 2: e832.

31. Gidlöf O, Smith JG, Melander O, Lövkvist H, Hedblad B, et al. (2012) A common missense variant in the ATP receptor $\mathrm{P} 2 \mathrm{X} 7$ is associated with reduced risk of cardiovascular events. PLoS One 7: e37491.

32. Purcell S, Neale B, Todd-Brown K, Thomas L, Ferreira MA, et al. (2007) PLINK: a tool set for whole-genome association and population-based linkage analyses. Am J Hum Genet 81: 559-575

33. Niculescu AB, Le-Niculescu $H$ (2010) The P-value illusion: how to improve (psychiatric) genetic studies. Am J Med Genet B Neuropsychiatr Genet 153B: 847-849.

34. Kremen WS, Seidman LJ, Pepple JR, Lyons MJ, Tsuang MT, et al. (1994) Neuropsychological risk indicators for schizophrenia: a review of family studies. Schizophr Bull 20: 103-119.

35. Hariri S, Yoon PW, Qureshi N, Valdez R, Scheuner MT, et al. (2006) Family history of type 2 diabetes: a population-based screening tool for prevention? Genet Med 8: 102-108.

36. Lappalainen T, Hannelius U, Salmela E, von Döbeln U, Lindgren CM, et al. (2009) Population structure in contemporary Sweden--a Y-chromosomal and mitochondrial DNA analysis. Ann Hum Genet 73: 61-73.

37. Humphreys K, Grankvist A, Leu M, Hall P, Liu J, et al. (2011) The genetic structure of the Swedish population. PLoS One 6: e22547.

38. Bodén R, Edman G, Reutfors J, Ostenson CG, Osby U (2013) A comparison of cardiovascular risk factors for ten antipsychotic drugs in clinical practice. Neuropsychiatr Dis Treat 9: 371-377.
39. Mathews M, Muzina DJ (2007) Atypical antipsychotics: new drugs, new challenges. Cleve Clin J Med 74: 597-606.

40. Bajaj S, Varma A, Srivastava A, Verma AK (2013) Association of metabolic syndrome with schizophrenia. Indian J Endocrinol Metab 17: 890-895.

41. Hennekens $\mathrm{CH}$ (2007) Increasing global burden of cardiovascular disease in general populations and patients with schizophrenia. J Clin Psychiatry 68 Supp 4: 4-7.

42. Ryan MC, Collins P, Thakore JH (2003) Impaired fasting glucose tolerance in first-episode, drug-naive patients with schizophrenia. Am J Psychiatry 160: 284-289.

43. Fernandez-Egea E, Miller B, Bernardo M, Donner T, Kirkpatrick B (2008) Parental history of type 2 diabetes in patients with nonaffective psychosis Schizophr Res 98: 302-306.

44. Mukherjee S, Schnur DB, Reddy R (1989) Family history of type 2 diabetes in schizophrenic patients. Lancet 1: 495.

45. Cederberg H, Stančáková A, Kuusisto J, Laakso M, Smith U (2014) Family history of type 2 diabetes increases the risk of both obesity and its complications: is type 2 diabetes a disease of inappropriate lipid storage? J Intern Med

46. Marder SR, Essock SM, Miller AL, Buchanan RW, Casey DE, et al. (2004) Physical health monitoring of patients with schizophrenia. Am J Psychiatry 161 1334-1349.

47. Haupt DW, Newcomer JW (2002) Abnormalities in glucose regulation associated with mental illness and treatment. J Psychosom Res 53: 925-933.

48. El-Seweidy MM, Sadik NA, Malek MM, Amin RS (2014) Chronic effects of clozapine administration on insulin resistance in rats: evidence for adverse metabolic effects. Pathol Res Pract 210: 5-9.

49. Hammer NA, Hansen Tv, Byskov AG, Rajpert-De Meyts E, Grøndahl ML, et al. (2005) Expression of IGF-II mRNA-binding proteins (IMPs) in gonads and testicular cancer. Reproduction 130: 203-212.

50. Christiansen J, Kolte AM, Hansen Tv, Nielsen FC (2009) IGF2 mRNA-binding protein 2: biological function and putative role in type 2 diabetes. $\mathrm{J}$ Mol Endocrinol 43: 187-195.

51. Zeggini E, Weedon MN, Lindgren CM, Frayling TM, Elliott KS, et al. (2007) Replication of genome-wide association signals in UK samples reveals risk loci for type 2 diabetes. Science 316: 1336-1341.

52. Tabara Y, Osawa H, Kawamoto R, Onuma H, Shimizu I, et al. (2009) Replication study of candidate genes associated with type 2 diabetes based on genomewide screening. Diabetes 58: 493-498.

53. Zhang X, Hui L, Liu Y, Wang ZQ, You Y, et al. (2013) The type 2 diabetes mellitus susceptibility gene IGF2BP2 is associated with schizophrenia in a Han Chinese population. J Clin Psychiatry 74: e287-292.

54. Gu T, Horová E, Möllsten A, Seman NA, Falhammar H, et al. (2012) IGF2BP2 and IGF2 genetic effects in diabetes and diabetic nephropathy. J Diabetes Complications 26: 393-398.

55. Jonsson A, Ladenvall C, Ahluwalia TS, Kravic J, Krus U, et al. (2013) Effects of common genetic variants associated with type 2 diabetes and glycemic traits on Ît- and $\hat{~}^{2}$-cell function and insulin action in humans. Diabetes 62: 2978-2983.

56. Reinehr T, Scherag A, Wang HJ, Roth CL, Kleber M, et al. (2011) Relationship between MTNR1B (melatonin receptor 1B gene) polymorphism rs10830963 and glucose levels in overweight children and adolescents. Pediatr Diabetes 12: $435-441$

57. Lucae S, Salyakina D, Barden N, Harvey M, Gagné B, et al. (2006) P2RX7, a gene coding for a purinergic ligand-gated ion channel, is associated with major depressive disorder. Hum Mol Genet 15: 2438-2445.

58. Backlund L, Lavebratt C, Frisén L, Nikamo P, Hukic Sudic D, et al. (2012) P2RX7: expression responds to sleep deprivation and associates with rapid cycling in bipolar disorder type 1. PLoS One 7: e43057.

59. Solini A, Chiozzi P, Morelli A, Adinolfi E, Rizzo R, et al. (2004) Enhanced P2X7 activity in human fibroblasts from diabetic patients: a possible pathogenetic mechanism for vascular damage in diabetes. Arterioscler Thromb Vasc Biol 24: $1240-1245$

60. Ursu D, Ebert P, Langron E, Ruble C, Munsie L, et al. (2014) Gain and loss of function of $P 2 X 7$ receptors: mechanisms, pharmacology and relevance to diabetic neuropathic pain. Mol Pain 10: 37 
Citation: Hukic DS, Olsson E, Hilding A, Ostenson CG, Gu HF, et al. (2015) Genes Associated with Increased Fasting Glucose in Patients with Schizophrenia Spectrum Disorders. J Diabetes Metab 6: 512. doi:10.4172/2155-6156.1000512

61. Bonnycastle LL, Chines PS, Hara T, Huyghe JR, Swift AJ, et al. (2013) Autosomal dominant diabetes arising from a Wolfram syndrome 1 mutation. Diabetes 62: 3943-3950

62. Itokawa M, Kasuga T, Yoshikawa T, Matsushita M (2004) Identification of a male schizophrenic patient carrying a de novo balanced translocation, $t(4 ; 13)$ (p16.1; q21.31). Psychiatry Clin Neurosci 58: 333-337.

63. Schleinitz D, Tönjes A, Böttcher Y, Dietrich K, Enigk B, et al. (2010) Lack of significant effects of the type 2 diabetes susceptibility loci JAZF, CDC123/ CAMK1D, NOTCH2, ADAMTS9, THADA, and TSPAN8/LGR5 on diabetes and quantitative metabolic traits. Horm Metab Res 42: 14-22.

64. Gaiano N, Fishell G (2002) The role of notch in promoting glial and neural stem cell fates. Annu Rev Neurosci 25: 471-490.

65. Shin HD, Park BL, Kim LH, Jung HS, Cho YM, et al. (2004) Genetic polymorphisms in peroxisome proliferator-activated receptor delta associated with obesity. Diabetes 53: 847-851.
66. Hu C, Jia W, Fang Q, Zhang R, Wang C, et al. (2006) Peroxisome proliferatoractivated receptor (PPAR) delta genetic polymorphism and its association with insulin resistance index and fasting plasma glucose concentrations in Chinese subjects. Diabet Med 23: 1307-1312.

67. Sun SL, Liu Y, Wei J, Liu SZ, Ju GZ (2008) The PPARD gene may be associated with schizophrenia in a Chinese population. Psychiatr Genet 18: 253-254.

68. Forman BM, Chen J, Evans RM (1997) Hypolipidemic drugs, polyunsaturated fatty acids, and eicosanoids are ligands for peroxisome proliferator-activated receptors alpha and delta. Proc Natl Acad Sci U S A 94: 4312-4317.

69. Arvindakshan M, Sitasawad S, Debsikdar V, Ghate M, Evans D, et al. (2003) Essential polyunsaturated fatty acid and lipid peroxide levels in nevermedicated and medicated schizophrenia patients. Biol Psychiatry 53: 56-64. 